\title{
AN EXPERIMENTAL STUDY OF THE PHOTOCATALYTIC HYDROGEN PRODUCTION IN THE LABORATORY-SCALE SET-UP DEPENDING ON THE PROCESS CONDITIONS
}

\author{
MAREK STELMACHOWSKI, KATARZYNA BEDNARCZYK \\ \& MARTA GMUREK \\ Faculty of Process and Environmental Engineering, Lodz University of Technology, Lodz, Poland
}

\begin{abstract}
Concern for the environment and the use of renewable energy sources are the two main priorities of energy policy combined with an environmental policy that is based on the principles of sustainable development. Many aspects should be taken into account in the case of energy production based on biomass/biofuels, in particular, the possibility of the formation of additional by-products. Glycerol is the main by-product during the trans-esterification of vegetable oils to biodiesel. The photocatalytic hydrogen production from the glycerol-water solution is less energy consuming reaction in comparison (for example) with its steam reforming or bio-conversion because it can be processed under mild conditions and low temperature. The paper presents the experimental results of the application process of photocatalytic hydrogen production from an aqueous solution of glycerol, with the use of $\mathrm{TiO}_{2}$ doped with noble metals (platinum, palladium, silver) as a photocatalyst under solar-like light irradiation. The aim was to compare the hydrogen productivity depending on the catalyst concentration, the kind of the doped metal and the amount of the metal in the catalyst. The reaction (glycerol-water with suspended catalyst) mixture was irradiated by Xe-arc lamps $(100 \mathrm{~W})$. The influence of the doped metal on the hydrogen yield was studied for the photocatalysts prepared by the sol-gel and photodeposition method. The photocatalysts have been studied using scanning electron microscopy (SEM) with EDX (Quanta FEI 200F, Oxford Instruments X-Max50), X-ray powder diffraction analysis (XRD) and X-ray photoelectron spectroscopy (XPS). It was proved, that glycerol is a good and efficient substance for the photocatalytic hydrogen production. The prepared and studied photocatalysts are characterized by high stability and very high yield under used process conditions. The experiments were performed in the quartz reactor with volume $1200 \mathrm{~cm} 3$. The volume of the reaction solution containing aqueous glycerol solution was $600 \mathrm{~cm}^{3}$. The maximum hydrogen production was about 269.13.10-3 [mole H2/(h.gcat)] and it was observed for $\mathrm{TiO}_{2}$ doped by platinum ( $1 \%$ by weight; prepared by photodeposition) for $4.5 \%$ aqueous solution of glycerol.
\end{abstract}

Keywords: photocatalytic, conversion, photocatalyst, hydrogen, glycerol.

\section{INTRODUCTION}

Various by-products are generated during the production of bio-diesel from plant oils. The most important one, obtained during oil transesterification, is crude glycerol. The increase of the production of biodiesel and the resulting excessive amount of glycerol produced by the transesterification of oils have led to considerable lower market prices of glycerol [1]. This will also decrease the profitability of the production of bioesters unless new glycerol utilizations are found. The literature data indicate that the (aqueous/steam) reforming of glycerol, photocatalytic conversion as well bio-conversion may prove to be the best processes for the utilization of glycerol from an economic and environmental point of view. In our opinion, photocatalytic conversion of it and simultaneously carried out water splitting is the best way to produce hydrogen. Glycerol and/or other alcohols are often used as sacrificial agents in the hydrogen process production, because can react irreversibly with the photoinduced holes, to achieve higher efficiency [2]-[4]. The rate of hydrogen production 
from glycerol depends on: the type of the catalyst, its amount in the solution, glycerol concentration and the intensity of irradiation [1], [2], [5], [6].

\section{MATERIAL AND METHODS}

\subsection{Materials}

All reagents used in this work were of analytical grade and were used without any further purification. Glycerol $(\geq 99 \%)$ was purchased from Sigma-Aldrich. All solutions were prepared using water from a Millipore system (Direct-Q ${ }^{\circledR}$ Water Purification System- Merck Millipore). Argon (Ar- gas: purity $>99 \%$ ) was purchased from Air Products.

\subsection{Catalysts preparation}

\subsubsection{Reagents}

Titanium (IV) isopropoxide (TIP) (97\%) was purchased from Aldrich Chem. And used as a titanium source for the preparation of $\mathrm{TiO}_{2}$ nanoparticles. A commercial form of $\mathrm{TiO}_{2}(\mathrm{P} 25$, crystalline composition: $80 \%$ anatase, $20 \%$ rutile, surface area $50 \mathrm{~g} / \mathrm{m}^{2}$ ) was from Evonik, Germany. $\mathrm{PdCl}_{2}\left(5\right.$ wt.\% solution in 10 wt. \% $\mathrm{HCl}$ ), $\mathrm{NH}_{2} \mathrm{NH}_{2} * \mathrm{H}_{2} \mathrm{O}$ (reagent grade $50-60 \%$ ), $\mathrm{H}_{2} \mathrm{PtCl}_{6}(99 \%)$ and $\mathrm{AgNO}_{3}(99 \%)$ from Sigma Aldrich were used as metal source in the preparation procedure. Ethanol (99,8\%) was purchased from POLCHEM (Poland).

The photocatalysts based on $\mathrm{TiO}_{2}$ were obtained by two methods:

1. a) sol-gel method (titania doped with transition metals).

2. b) photodeposition of noble metals at the surface of P25.

\subsubsection{The photodeposition method}

All the photocatalysts were obtained by UV-reduction of $\mathrm{Pt}^{4+}, \mathrm{Pd}^{2+}, \mathrm{Ag}$ ions in the $\mathrm{TiO}_{2}$ suspension. $70 \mathrm{~cm}^{3}$ of ethanolic solution- containing $\mathrm{TiO}_{2}$ nanosheets $(2 \mathrm{~g})$ and metal precursor $(0.1 ; 0.5 ; 1 \%(\mathrm{~m} / \mathrm{m})$ was sonicated for $10 \mathrm{~min}$, stirring in dark for $2 \mathrm{~h}$, degassed with nitrogen in dark for $1 \mathrm{~h}$ and finally illuminated by $1000 \mathrm{~W}$ Xe lamp. An aqueous solution of isopropanol containing $\mathrm{H}_{2} \mathrm{PtCl}_{6}\left(0.5\right.$ wt. \%) or $\mathrm{PdCl}_{2}(0.5$ wt. \%) was degassed with nitrogen and irradiated by UV-Vis light (1000 W Xe lamp) for $6 \mathrm{~h}$. An aqueous solution of ethanol containing $\mathrm{AgNO}_{3}(0,1 ; 0.5 ; 1$ wt. \%) was degassed with nitrogen and irradiated by UV-Vis light (1000 W Xe lamp) for $100 \mathrm{~min}$. The modified $\mathrm{TiO}_{2}$ photocatalysts were separated by centrifugation and dried at $65-120^{\circ} \mathrm{C}$ for $12 \mathrm{~h}$.

Metal ion concentration [M]:

$$
\begin{aligned}
& \text { 1. dla Ag } 0.1 \%, 0.5 \%, 1 \%\left(3.98 \times 10^{-4}, 1,99 \times 10^{-3}, 3,98 \times 10^{-3}\right) \\
& \text { 2. dla Pd } 0.1 \%, 0.5 \%, 1 \%\left(4.02 \times 10^{-4}, 2.01 \times 10^{-3}, 4.02 \times 10^{-3}\right) \\
& \text { 3. dla Pt } 0.1 \%, 0.5 \%, 1 \%\left(2.2 \times 10^{-4}, 1.1 \times 10^{-3}, 2.2 \times 10^{-3}\right)
\end{aligned}
$$

\subsubsection{The sol-gel method}

$\mathrm{Au}$ - modified $\mathrm{TiO} 2$ was prepared from titanium (IV) isopropoxide, known to be the titanium source origin for the anatase-type $\mathrm{TiO} 2$. Anatase titanium dioxide nanoparticles were prepared by the hydrolysis reaction of TIP with water. $35 \mathrm{ml}$ of titanium (IV) isopropoxide was added to $35 \mathrm{ml}$ of ethanol and next metal precursor - $(0.1 \% ; 0.5 \%) \mathrm{KAuCl} 4(\mathrm{~m} / \mathrm{m})$ and the mixture was stirred for $5 \mathrm{~min}$ using a magnetic stirrer operating at $500 \mathrm{rpm}$. Next, 11.63 $\mathrm{ml}$ of distilled water was added to the mixture and was stirred for $1 \mathrm{~h}$. After stirring, distilled water and hydrazine were added to the mixture and thick precipitate was formed which 
gradually peptized for $2 \mathrm{~h}$ to form a clear sol, followed by a 24 hour thermal treatment $\left(45^{\circ} \mathrm{C}\right)$ and calcination at $400^{\circ} \mathrm{C}$ for $2 \mathrm{~h}$.

\subsection{Catalysts characterization}

The structure of the photocatalyst was characterized by XRD (X-ray diffraction). The measurement of the powder X-ray diffraction was performed on X-ray diffractometer Philips $X$ 'Pert Pro MPD equipped with a copper X-ray tube, $\lambda(\mathrm{Cu} \mathrm{K} \alpha)=1.54 \AA$. The resulting diffraction patterns were then analyzed using HighScore Plus. The surface area of catalysts, Brunauer-Emmet-Teller (SBET) was analyzed using nitrogen $\left(-196^{\circ} \mathrm{C}\right)$ with an accelerated surface area and porosimetry analyzer CASAP 2000, Micrometrics.

The XPS (X-ray photoelectron spectroscopy) analyses were carried out with a Kratos AXIS Ultra spectrometer using monochromatic $\mathrm{Al} \mathrm{K \alpha} \mathrm{X}$-Rays source of excitation energy equal to $1486.6 \mathrm{eV}$. The spectra were obtained using an analysis area of $300 \mu \mathrm{m} \times 700 \mu \mathrm{m}$. The power of the anode was set at $150 \mathrm{~W}$ and the hemispherical electron energy analyzer was operated at a pass energy of $20 \mathrm{eV}$ for all high-resolution measurements. The use of a charge neutralizer during spectra collecting was necessary due to the insulating character of the samples. Reproducibility was ensured by taking more than three measurements per analyzed sample.

The microstructural analysis of the surface and particles average diameter was performed using a TESCAN VEGA 3 SBH - Easy Probe Scanning Electron Microscopy (SEM) with a tungsten heated cathode and SEM+EDX (Quanta FEI 200F, Oxford Instruments XMax50).

The BET (Brunauer-Emmet-Teller $\left(\mathrm{S}_{\mathrm{BET}}\right)$ ) specific surface area of the catalysts were analyzed using nitrogen $\left(-196^{\circ} \mathrm{C}\right)$ with an accelerated surface area and porosimetry analyzer (ASAP 2000, Micrometrics).

\subsection{The experimental procedures of the performed photocatalytic tests}

All the experiments of the process of photocatalytic conversion of glycerol into hydrogen were carried out in the quartz reactor with the volume $1200 \mathrm{~cm}^{3}$ that was cooled by water. The volume of the aqueous solution of glycerol with suspended photocatalyst was $600 \mathrm{~cm}^{3}$. The Xe-arc lamp $(100 \mathrm{~W})$ was placed in the vertical axis of the reactor. The lamp was used as a source of energy and to simulate sunlight. The temperature of the reaction mixture at the beginning of the runs was $25^{\circ} \mathrm{C}$ and during the experiments increased up to $30^{\circ} \mathrm{C}$. Argon with the flow rate equal to $150\left(\mathrm{~cm}^{3} / \mathrm{min}\right)$ was used as a carrier gas in all tests. The suspension of the catalyst in the reaction mixture was obtained by stirring (magnetic stirrer), as well as through the (bubbling) flow of argon. The stream of flowing argon enabled also the removal of the dissolved oxygen (that was present in the system before the start the experiments and that was produced in the simultaneous water splitting) as well the removal of hydrogen and carbon dioxide produced in the process of glycerol conversion. The scheme of the laboratory set-up is shown in Fig. 1. Each of the experiments lasted approximately 4-6 hours. The process conditions of the carried out test runs are presented in Table 1. 


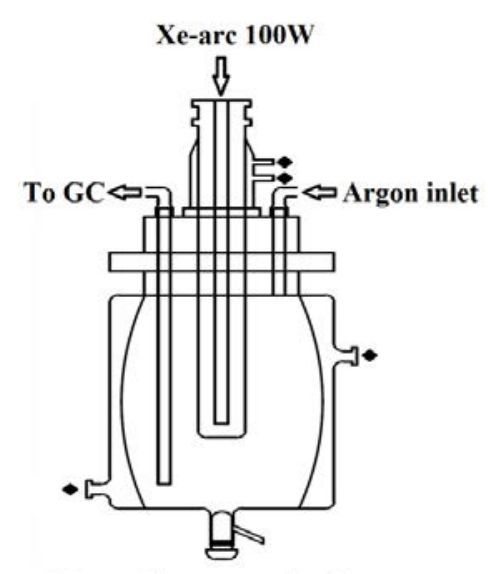

- The cooling water circuit

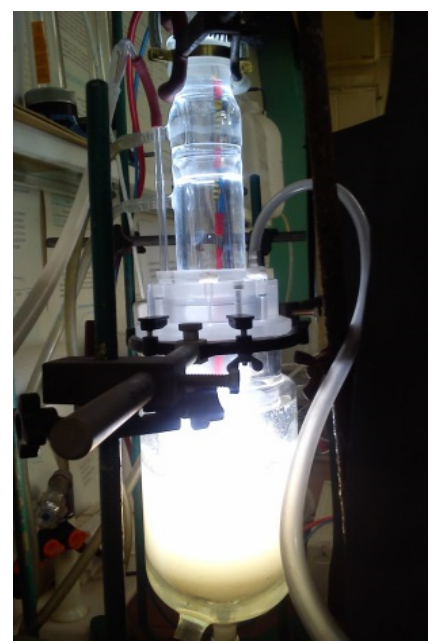

Figure 1: The scheme and the photo of the quartz reactor with cooling and the lamp placed in the vertical axis of the reactor.

Table 1: Process conditions for the process of hydrogen from glycerol.

\begin{tabular}{|c|c|c|c|c|c|}
\hline $\begin{array}{c}\text { The volume } \\
\text { of the } \\
\text { reactor } \\
\left(\mathrm{cm}^{3}\right)\end{array}$ & $\begin{array}{c}\text { The volume } \\
\text { of the } \\
\text { reaction } \\
\text { solution } \\
\left(\mathrm{cm}^{3}\right)\end{array}$ & $\begin{array}{c}\text { Glycerol } \\
\text { initial } \\
\text { concentration } \\
(\text { wt. } \%)\end{array}$ & $\begin{array}{c}\text { Power the } \\
\text { light source } \\
(\mathrm{W})\end{array}$ & $\begin{array}{c}\text { The } \\
\text { temperature } \\
\text { of the } \\
\text { reaction } \\
\text { mixture }\left({ }^{\circ} \mathrm{C}\right)\end{array}$ & $\begin{array}{c}\text { Argon flow } \\
\text { rate } \\
\left(\mathrm{cm}^{3} / \mathrm{min}\right)\end{array}$ \\
\hline 1200 & 600 & 4.5 & 100 & $25-30$ & 150 \\
\hline
\end{tabular}

\subsection{The analytical methods}

The gas chromatograph (Perkin Elmer) equipped with a TCD detector was used for the analysis of the gas phase (on line). The injection volume of the gas sample was $1 \mathrm{~cm}^{3}$. The evolved gases were analysed every 15 minutes using a gas chromatograph (using an Altech silica gel Packed Columns 5651 PC). The chromatographic conditions were as follows: injector port temperature of $200{ }^{\circ} \mathrm{C}$, detector temperature of $220^{\circ} \mathrm{C}$, a temperature program of $120^{\circ} \mathrm{C}$ for $3.5 \mathrm{~min}$, ramp up to $180^{\circ} \mathrm{C}$ at $40^{\circ} \mathrm{C} / \mathrm{min}$., and then held for $4 \mathrm{~min}$.

\section{RESULTS AND DISCUSSION}

\subsection{Catalysts characterization}

\subsubsection{Determination of the surface of the catalyst}

The SEM + EDX electron microscope (Quanta FEI 200F, Oxford Instruments X-Max50) was used to determine the nature of the surface of the catalyst test sample. The microscope resolution is $1.2 \mathrm{~nm}$ and allows accurate imaging of objects ranging in size from tens of $\mathrm{nm}$. The EDX adapter allows you to determine the composition of the element of the test material and to determine the topography of the decomposition of the elements on the surface of the sample. 


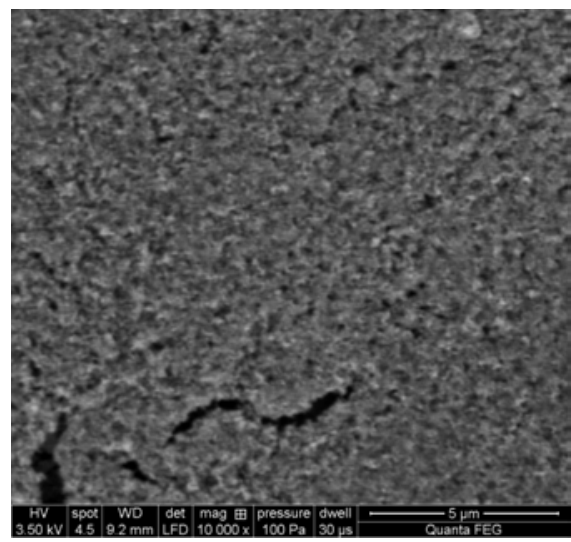

a)

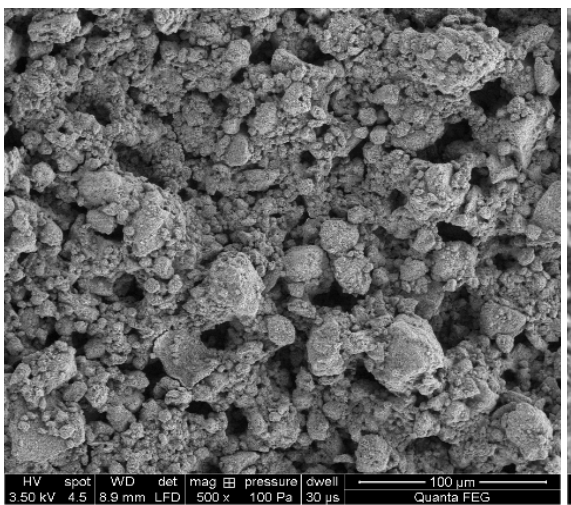

c)

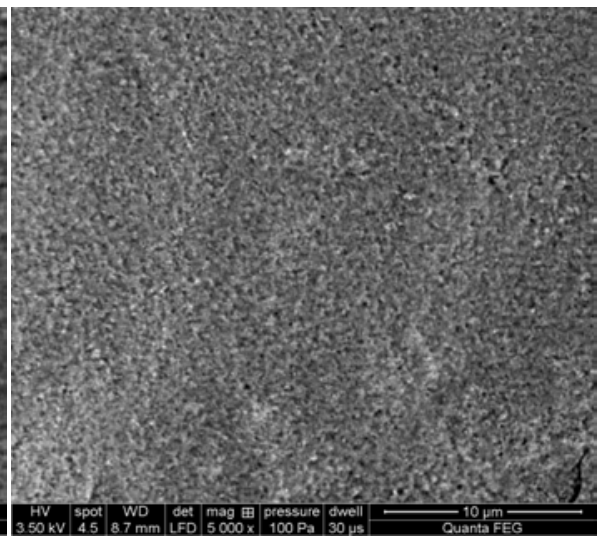

b)

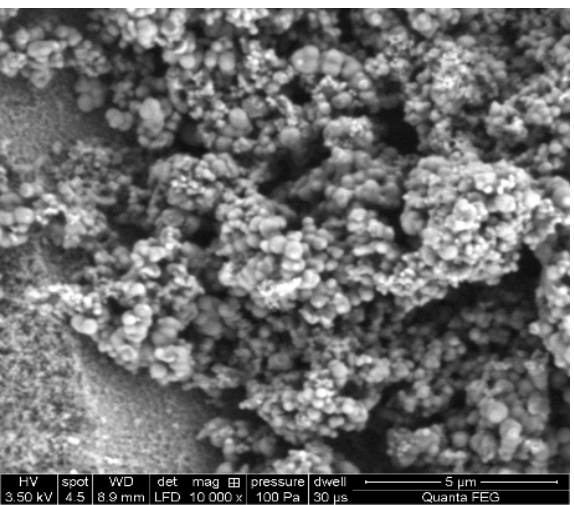

d)

Figure 2: SEM images of different catalyst materials. (a) $-0.5 \mathrm{Pt} / \mathrm{TiO} 2$; (b) $-0.5 \mathrm{Pd} / \mathrm{TiO} 2$; (c) $-0.5 \mathrm{Ag} / \mathrm{TiO} 2$ - all prepared by the photodeposition method and (d) -0.5 $\mathrm{Pt} / \mathrm{TiO} 2$ - prepared by the sol-gel method.

The basic principle of operation of the microscope to obtain an image is to subject the analyzed sample to scanning by means of a directed electron stream. For a given test material a signal is generated which is emitted and recorded by suitable detectors and then processed into the image. Microsphere cluster formation (rounded crystalline forms of irregular size) was observed. The photocatalyst is characterized by the uneven distribution of metal particles, which create places of high density. SEM images are presented in Fig. 2.

\subsubsection{The XRD analysis of the catalysts}

The XRD patterns of the photocatalyst doped with platinum and palladium $(0.1$ wt. $\%, 0.5$ wt. \%) prepared by photodeposition are presented in Fig. 3. For all samples, two phases (anatase and rutile) of $\mathrm{TiO}_{2}$ were observed. The percentages of the phases did not depend on the amount of dopant and are composed of $80 \mathrm{wt} . \%$ (anatase) and $20 \mathrm{wt}$. \% (rutile). The strongest reflexes for rutile were observed at 27.5 deg. (marked by \# - in Fig. 3). 

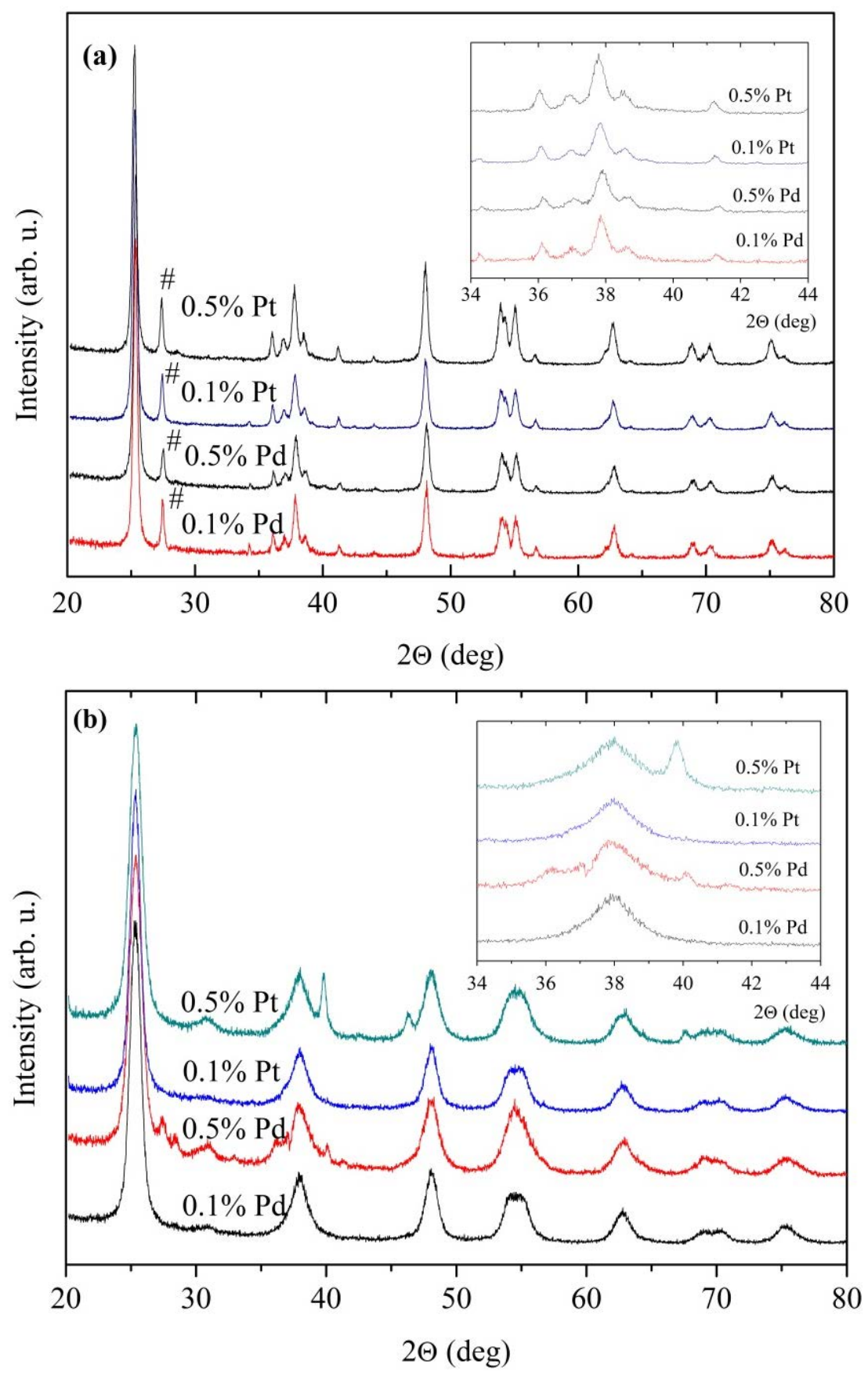

Figure 3: $\mathrm{XRD}$ analysis for $\mathrm{Pt} / \mathrm{TiO}_{2}$ and $\mathrm{Pd} / \mathrm{TiO}_{2}$ catalysts prepared by: (a) photodeposition method; (b) sol-gel method. 
Table 2: Relative elemental concentrations obtained from the XPS composition analysis.

\begin{tabular}{|c|c|c|c|c|}
\hline $\begin{array}{c}\text { Catalysts } \\
\mathrm{Me} / \mathrm{TiO}_{2}\end{array}$ & $\mathrm{O}$ (wt. \%) & $\mathrm{Ti}$ (wt. \%) & $\mathrm{C}$ (wt. \%) & Me content (wt. \%) \\
\hline $0.1 \mathrm{Pt} / \mathrm{TiO}_{2}$ & $48.57 \pm 0.43$ & $21.11 \pm 0.17$ & $30.25 \pm 0.59$ & $0.08 \pm 0.01$ \\
\hline $\begin{array}{c}0.5 \mathrm{Pt} / \mathrm{TiO}_{2} \\
\mathrm{PD}\end{array}$ & $48.70 \pm 0.55$ & $20.73 \pm 0.01$ & $30.46 \pm 0.54$ & $0.13 \pm 0.01$ \\
\hline $\begin{array}{c}0.5 \mathrm{Pd} / \mathrm{TiO}_{2} \\
\mathrm{PD}\end{array}$ & $55.88 \pm 0.05$ & $23.66 \pm 0.62$ & $20.24 \pm 0.66$ & $0.23 \pm 0.01$ \\
\hline $\begin{array}{c}0.5 \mathrm{Ag} / \mathrm{TiO}_{2} \\
\mathrm{PD}\end{array}$ & $58.63 \pm 0.66$ & $23.84 \pm 0.25$ & $17.06 \pm 0.88$ & $0.47 \pm 0.04$ \\
\hline $\begin{array}{c}0.1 \mathrm{Pt} / \mathrm{TiO}_{2} \\
\text { sol-gel }\end{array}$ & $47.85 \pm 0.39$ & $20.19 \pm 0.04$ & $31.89 \pm 0.36$ & $0.09 \pm 0.01$ \\
\hline $\begin{array}{c}0.5 \mathrm{Pt} / \mathrm{TiO}_{2} \\
\text { sol-gel }\end{array}$ & $48.70 \pm 0.55$ & $20.73 \pm 0.01$ & $30.46 \pm 0.54$ & $0.13 \pm 0.01$ \\
\hline
\end{tabular}

With increasing concentration of the Pt, the crystallite size appears to be increasing (from $196 \mathrm{~nm}$ to $220 \mathrm{~nm}$ ) for the anatase form and decreasing (from $415 \mathrm{~nm}$ to $216 \mathrm{~nm}$ ) for the rutile form. Test samples contain anatase, but brookite is present in place of rutile, which is the dominant phase for sample $25(0.5 \% \mathrm{Pt})$. Brookit crystallizes in the orthorhombic structure with low symmetry (spatial group 61), resulting in many diffraction reflections. The most intense reflections almost coincide with the strongest anatase reflection (about 25.3 deg.), which complicates LeBail's analysis.

3.2 A methodology for identifying the chemical composition of the surface analysis by XPS

Relative concentrations of elements in modified of catalysts are presented in Table 2. Morphological and surface characterization of the sample $\left(\mathrm{Pt} / \mathrm{TiO}{ }_{2}, \mathrm{Pd} / \mathrm{TiO}_{2}\right.$ and $\left.\mathrm{Ag} / \mathrm{TiO}_{2}\right)$ were studied earlier and published in our previous papers [7], [8].

\subsection{The photocatalytic hydrogen production tests}

The comparison of the influence of kind of the doped metal and its amount in the catalyst $\left(\mathrm{TiO}_{2}\right)$ on $\mathrm{H}_{2}$ productivity in the glycerol solution (4.5 wt. \%) was studied for the photocatalysts prepared by the both methods: the photodeposition as well as the sol-gel method. The hydrogen productivity in the performed runs for different catalysts is presented in Fig. 4. As it can be noticed, the productivity of hydrogen in the system with pure $\mathrm{TiO} 2$ is very small while for the catalysts doped by the noble metals the productivity was essential higher. It also can be seen that the obtained effect for of the catalysts prepared by the photodeposition method were significantly better. 

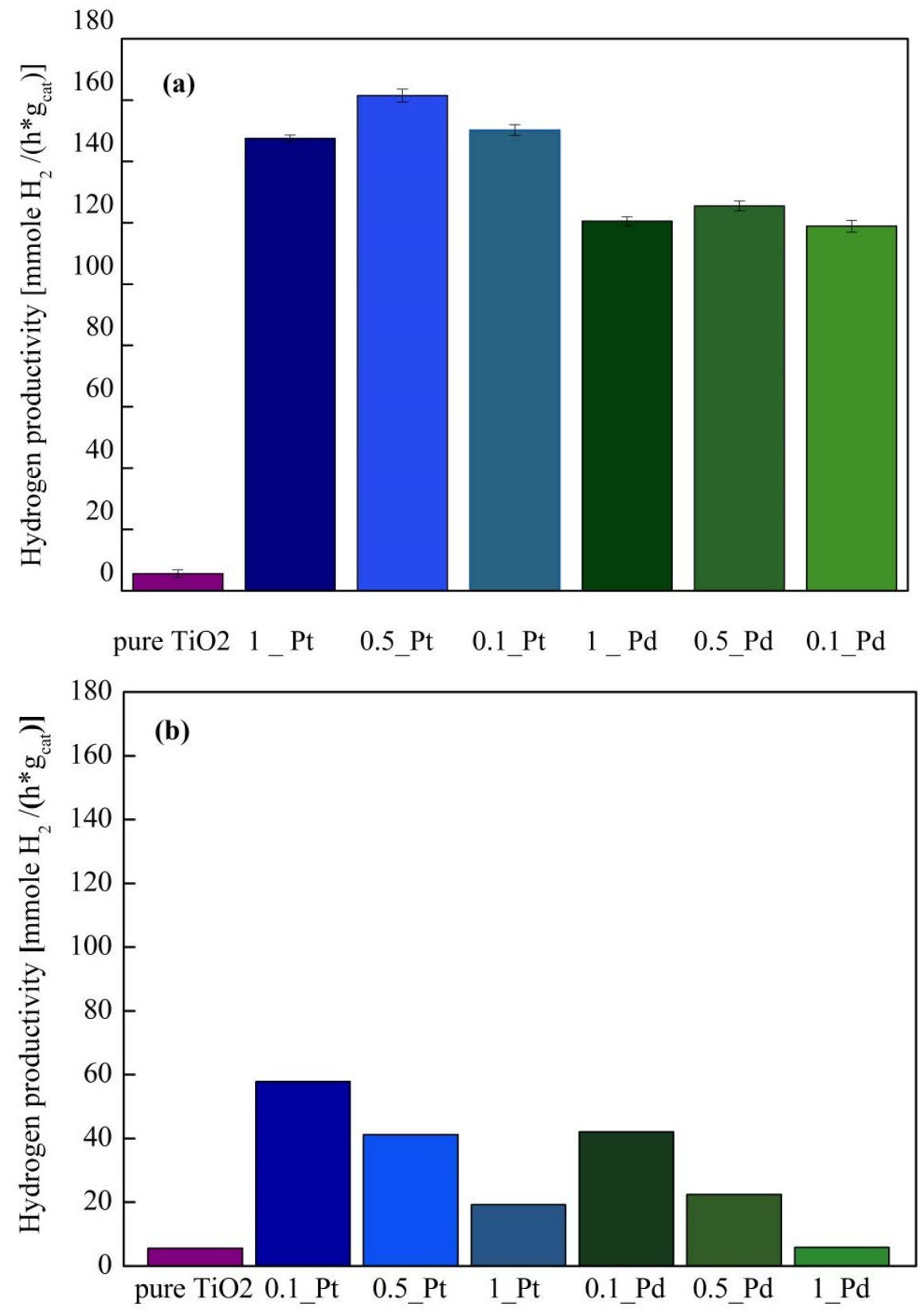

Figure 4: Hydrogen productivity for different of catalyst prepared by the photodeposition method. (a) and by the sol-gel method (b); Concentration of the catalyst in the glycerol solution was equal to $0.083 \mathrm{~g} / \mathrm{L}$ and concentration of glycerol was $4.5 \mathrm{wt}$. $\%$ in the all cases. 


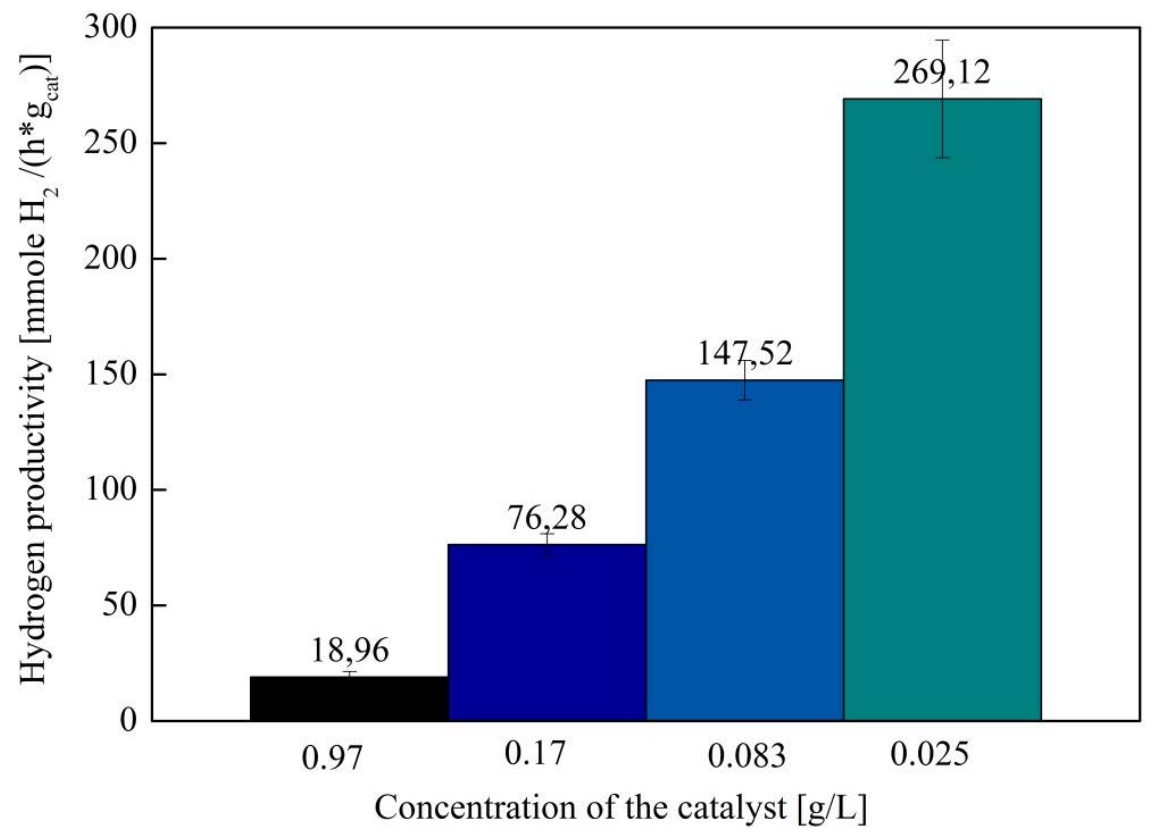

Figure 5: The productivity of hydrogen for different concentrations of the catalyst; the reaction solution: $4.5 \mathrm{wt}$ \% of glycerol); catalyst: $\mathrm{Pt} / \mathrm{TiO}_{2}(1 \mathrm{wt} . \%)$ prepared by the photodeposition method.

The influence of the amount of photocatalyst (the concentration of the catalyst in the reaction mixture) added to the solution was also studied. The volume of the reaction mixture was equal to $600 \mathrm{~cm}^{3}$. The distribution of light dispersion depends on the amount of the photocatalyst and has a large impact on the performance of hydrogen production. In our opinion, already a very small amount of the catalyst in the solution may be enough to reach the high hydrogen productivity. As we can see in Fig. 5, the highest productivity of H2 was obtained for the lowest concentration of the catalyst that was possible to prepare by us.

The influence of the intensity of the lamps was also studied and analysed for the $\mathrm{Pt} / \mathrm{TiO} 2$ obtained by photodeposition. The obtained results, that the intensity of radiation has an essential influence on the efficiency of hydrogen production. The study and results are in progress and they will be presented in our future papers.

\section{CONCLUSIONS}

- The preparation method has a significant effect on the catalytic properties of the material used as a catalyst. The obtained results favour the use of the photodeposition method.

- In the investigated process, consisting of two simultaneous reactions: photocatalytic conversion of glycerin to hydrogen and photocatalytic cleavage of water, an optimum content of doped metal (to $\mathrm{TiO}_{2}$ ) may be observed. Experiments show that in the case of platinum it is about 0.5 percent by weight.

- Experiments have also shown that the preferred metal added to $\mathrm{TiO}_{2}$ is platinum. 
- The XRD analysis shows that for the catalyst produced by photodeposition there are two crystalline forms of $\mathrm{TiO}_{2}$ in the studied material: anatase and rutile in a ratio of about $4: 1$. For the catalyst prepared by the sol-gel method, the brookite form is also observed in the catalyst. It was not possible to determine the detailed ratio of these different forms of $\mathrm{TiO} 2$ for studied catalysts. No regularity was found.

\section{ACKNOWLEDGEMENT}

This study was performed as the statutory research at the Faculty of Process and Environmental Engineering (Lodz University of Technology) and was funded by The Ministry of Science and Higher Education

\section{REFERENCES}

[1] Stelmachowski, M., Marchwicka, M., Grabowska, E., Dial, M. \& Zaleska, A.M., The Photocatalytic Conversion of (Biodiesel Derived) Glycerol to Hydrogen - A Short Review and Preliminary Experimental Results, Part 1: A Review. J. Advanced Oxidation Technologies, 17(2), pp. 167-178, 2014.

[2] Colón, G., Towards the hydrogen production by photocatalysis, Applied Catalysis A: General, 518, pp. 48-59, 2016.

[3] Beltram, A., Romero-Ocana, I., Delgado, Jaen, J.J., Montinia, T. \& Fornasiero, P., Photocatalytic valorization of ethanol and glycerol over $\mathrm{TiO} 2$ polymorphs for sustainable hydrogen production, Applied Catalysis A: General, 518, pp. 167-175, 2016.

[4] López-Tenllado, F.J., Hidalgo-Carrillo, J., Montes, V., Marinas, A., Urbano, F.J., Marinas, J.M., Ilieva, L., Tabakov, T. \& Reid F., A comparative study of hydrogen photocatalytic production from glycerol and propan-2-ol on $\mathrm{M} / \mathrm{TiO} 2$ systems $(\mathrm{M}=\mathrm{Au}$, Pt, Pd), Catalysis Today 280, pp. 58-64, 2017.

[5] Fujita, S., Kawamori, H., Honda, D., Yoshida, H. \& Arai, M., Photocatalytic hydrogen production from aqueous glycerol solution using $\mathrm{NiO} / \mathrm{TiO} 2$ catalysts: Effects of preparation and reaction conditions, Applied Catalysis B: Environmental, 181, pp. 818824, 2016.

[6] Stelmachowski, M., Marchwicka, M., Grabowska, E., Dial, M. \& Zaleska, A.M The Photocatalytic Conversion of (Biodiesel Derived) Glycerol to Hydrogen - A Short Review and Preliminary Experimental Results, Part 2: Photocatalytic Conversion of Glycerol to Hydrogen in Batch and Semi-batch Laboratory Reactors. J. Advanced Oxidation Technologies, 17(2), pp. 179-186, 2014.

[7] Gomes, J.F., Leal, I., Bednarczyk, K., Gmurek M., Stelmachowski M., Diak M., Emília Quinta-Ferreira M., Costa R., Quinta-Ferreira R.M. \& Martins R.C., Photocatalytic ozonation using doped $\mathrm{TiO} 2$ catalysts for the removal of parabens in water. Science of the Total Environmental, 609, pp. 329-340, 2017.

[8] Gomes, J.F., Bednarczyk, K., Gmurek, M., Stelmachowski, M., Zaleska-Medyńska, A., Emília Quinta-Ferreira, M., Costa, R., Quinta-Ferreira, R.M. \& Martins, R.C., Noble metal-TiO2 supported catalysts for the catalytic ozonation of parabenns mixtures. Process Safety and Environental Protection III, pp. 148-159, 2017. 